\title{
Spatio-temporal variability of rainfall in a high tropical island: Patterns and large-scale drivers in Réunion Island
}

\author{
Anne Réchou ${ }^{1}$ | Olivier Flores ${ }^{2}$ | Guillaume Jumaux ${ }^{3}$ | Valentin Duflot ${ }^{1,4}$ | Olivier \\ Bousquet $^{1}$ | Chloé Pouppeville ${ }^{1}$ | Francois Bonnardot ${ }^{3}$
}

\author{
${ }^{1}$ Université de la Réunion, LACy, UMR 8105, La \\ Réunion, France \\ ${ }^{2}$ UMR C53 CIRAD/Université de La Réunion \\ Peuplements Végétaux et Bioagresseurs en Milieu \\ Tropical, Université de La Réunion, Saint Denis de \\ La Réunion, France \\ ${ }^{3}$ Météo-France, DIRE, La Réunion, France \\ ${ }^{4}$ Observatoire des Sciences de 1'Univers de La \\ Réunion, UMS3365, Saint-Denis de la Réunion, \\ France \\ Correspondence \\ Anne Réchou, Laboratoire de l'Atmosphère et des \\ Cyclones (LACy-UMR 8015, CNRS, Université de \\ La Réunion, Météo-France), 97744 Saint Denis de \\ La Réunion, France. \\ Email: arechou@univ-reunion.fr \\ Funding information \\ Overseas Ministry, EROVEG program. Réunion \\ University.
}

\begin{abstract}
Weather forecasting is challenging because of the complex interplay between local conditions and regional atmospheric forcings. In this article, we analyse the relationships between local daily rainfall and large-scale synoptic patterns in the geographical context of Réunion Island, a high volcanic island in the southwestern Indian Ocean basin. Given the critical role of trade winds on weather conditions at island scale, we analyse those relationships across seasons defined with respect to yearly trade-wind regimes. The analysis of the distribution of inversion events' elevation and frequency allows us to characterize the trade-wind inversion layer (TWIL) and identify four seasons with homogeneous distributions. We characterize the spatio-temporal variability of rainfall measured at island scale by a dense network of rain-gauges over 37 years and relate it to large-scale weather regimes identified using geopotential height meteorological data. After seasonal signal removal using Fourier transforms and dimension reduction via Principal Component Analysis, we perform Canonical Correlation Analysis to identify canonical variables relating rainfall and geopotential height patterns at the two different studied spatial scales. We then combine Ascending Hierarchical Classification and partitioning k-means methods to identify homogeneous large-scale synoptic conditions within each season. From this information, we build composite maps of geopotential height that characterize weather regimes and further analyse rainfall patterns at island scale in each regime. Elevation and orientation are used as descriptive variables at island scale as they strongly structure the patterns. Overall, four homogeneous seasons were identified based on trade-wind regimes, within which six large-scale weather regimes were identified for summer, the most variable season, and four for the others. Finally, rainfall patterns at island scale are described in relation to the highlighted synoptic regimes and local descriptive variables.
\end{abstract}

\section{KEYWORDS}

canonical correlation analysis, climatology, erosion, rain-gauge, rainfall, Réunion Island

\section{1 | INTRODUCTION}

As part of the water cycle, rainfall drives water fluxes from the atmosphere to the biosphere. It is a major process that impacts on multiple geological, hydrological and ecological processes. Rainfall influences both topography, through erosion, and vegetation development for instance. It allows groundwater recharge and increases water supply available for vegetation, which in turn releases water by evapotranspiration. Understanding rainfall variability is key to understand landscape-scale processes such as vegetation development and erosion. However, the task is challenging due to the complex nature of the factors influencing rainfall patterns; mountains for instance have strong influence as they can force 
the air to rise, leading to the formation of clouds and rainfall. It is moreover strikingly challenging on tropical small islands with complex topography (Hevesi et al., 1992). In an insular context, combined effects of regional drivers and complex orography strongly influence the distribution of rainfall.

In the small volcanic island of La Réunion $\left(21^{\circ} 08^{\prime} \mathrm{S}\right.$, $55^{\circ} 32^{\prime} \mathrm{E}$ ), as the local geographer says: "Nowhere else the morphology of a territory and the life of its inhabitants evolved at such a dizzying speed" (Robert, 1986). Réunion Island, which hosts the highest mountain summit in the Indian Ocean, is home to the majority of worldwide rainfall records at time-scales ranging from $30 \mathrm{~min}$ to 15 days (Quetelard et al., 2009). Rain erosion combined with active volcanism constantly redesigns the island's landscapes. However, and quite surprisingly, no local climatology of rainfall has been produced yet for this island. At island scale, rainfall patterns are mainly driven by large-scale atmospheric conditions, defined as synoptic weather patterns. For instance, when a tropical depression impacts Réunion Island, trade winds (TW) tend to bring heavy rainfall to the eastern part of the island. As different weather conditions differently affect the island throughout the year, local rainfall varies in time at any given location, but also in space as extreme values vary over short distances. How synoptic conditions affect local regional- or island-scale patterns is poorly understood.

Various statistical approaches can be used to analyse rainfall variability, such as the quantile perturbation method (QPM: Ntegeka and Willems, 2008; Willems, 2013) or empirical orthogonal functions (EOFs, also called principal component analysis, PCA). The EOF method decomposes multivariate time series into a set of uncorrelated, orthogonal components ordered according to their variance, from largest to smallest. Rodríguez-Puebla et al. (1998), for instance, used EOF to study the spatio-temporal variability of annual rainfall over the Iberian Peninsula (IP) for 47 years and 51 stations and found four regional rainfall regimes. Linking together multivariate patterns measured at different spatial scales is a challenging task. When daily meteorological conditions are characterized in two different datasets, at two different spatial scales for instance, canonical correlation analysis (CCA: Hotelling, 1936; Anderson, 1984) can be used to examine potential correlations between major axes of variation at both scales. The CCA method has been successfully applied to similar problems in many other fields of study (Andrew et al., 2013): chemometrics (Montanarella et al., 1995), biology and medicine (Vert and Kanehisa, 2004), sociology (natural language processing: Vinokourov et al., 2004, speech processing: Choukri and Chollet, 1986; Arora and Livescu, 2013), computing (computer vision: Kim et al., 2007, or multimodal signal processing: Sargin et al., 2007), meteorology (Binaku et al., 2013), among others. Using CCA, in a suburban area $5 \mathrm{~km}$ from Athens city centre $\left(37^{\circ} 58^{\prime} 10^{\prime \prime} \mathrm{N}\right.$, $23^{\circ} 47^{\prime} 11^{\prime \prime} \mathrm{E}, 240 \mathrm{~m}$ altitude above sea level (a.s.l.)), Halios et al. (2012) studied meteorological patterns under different synoptic scales using surface meteorological elements and meteorological variables at 850 and $700 \mathrm{hPa}$. Their results indicated that upper-air environment was strongly connected to thermodynamics of the surface with weak relationships with surface flow fields, demonstrating the influence of local topography. Martinez et al. (2008) used this method to investigate the relationships between large-scale atmospheric circulation and rainfall events over western Europe, and Littmann (2000) produced an empirical classification of weather types and evidenced their relationships with rainfall in the Mediterranean basin.

Numerous studies have highlighted the importance of linking the weather with the climate scientific communities in order to better address various issues and to improve semi-seasonal and seasonal predictions (Brunet et al., 2010; Shapiro et al., 2010).

A study by Macron et al. (2016) reported a general consistency between local-scale rainfall variability in Madagascar and regional-scale features of climate variability. On their part, Morel et al. (2014) analysed the capability of the Weather Research and Forecasting (WRF) regional climate model in regionalizing rainfall variability at very high resolution $(680 \mathrm{~m})$ over Réunion Island for daily to seasonal scales and year-to-year differences for two contrasted summer seasons (from November to April): 2000-2001 (abnormally dry) and 2004-2005 (abnormally wet). Comparison of model outputs with rain-gauge records showed that WRF is able to reproduce seasonal rainfall amounts, although larger differences could be noticed at the intraseasonal and daily time-scales.

In this context, the main goal of this article is to better understand how large-scale weather patterns influence rainfall spatio-temporal patterns through analysing synoptic weather patterns in relation with rainfall in time and space at local scale on Réunion Island.

The particularly dense rain-gauge network available at Réunion Island (54 rain-gauges over an area of 2,512 $\mathrm{km}^{2}$ ) allows studying the spatial variability of rain at temporal scales ranging from seasonal to diurnal, and spatial scales from mesoscale to local scale. Time series of daily rainfall measurements are analysed using multivariate methods (PCA and CCA). The article is organized as follows. Section 2 describes the characteristics of the island and its associated weather. Section 3 presents the data and methods used in this study. The results derived from the analysis of the rain-gauge data and large-scale geopotential height fields, in terms of seasonality, synoptic definition, and rainfall patterns for all seasons and all classes of synoptic conditions, are presented in section 4 , and discussion in section 5.

\section{2 | SPATIAL AND CLIMATE CHARACTERISTICS OF RÉUNION ISLAND}

Because of its location which is close to the Tropic of Capricorn $\left(21^{\circ} \mathrm{S}, \sim 55^{\circ} \mathrm{E}\right)$, Réunion Island is subject to a 
southeasterly trade-wind regime. These southeasterly trade winds carry large amounts of humidity and consequently significant rainfall almost all year long to the windward (eastern) side of the island. By contrast, the leeward (western) side receives much lower rainfall with a high seasonal variability. Thus, the western side is much drier and thermal winds occur often (sea and land breezes). These winds are controlled by temperature contrasts between land and sea on one side, and between lowland and highlands of the island on the other side (Lesouëf et al., 2011). There is a strong diurnal cycle associated with sea and land breeze, leading to cloud development along the higher parts of the island in the morning (often associated with rain). The clouds usually extend to coastal areas by midday.

In addition to the longitudinal contrast across the entire island, rainfall is highly variable in space due to the complex topography of the island that is the result of the easily eroded volcanic bedrock (basalt) and intense rainfall. Indeed, the island hosts deep canyons, ravines, steep ridges, calderas and two mountain peaks: the extinct volcano of Piton des Neiges (3070 m), the highest summit in the Indian Ocean, and the volcano Piton de la Fournaise (2632 m), one of the world's most active volcanoes.

During austral winter (May to November), thermal winds are stronger and a strong wind inversion layer occurs usually below $2200 \mathrm{~m}$. This prohibits the vertical development of clouds and rainfall above $1700 \mathrm{~m}$ (Réchou et al., 2014). Above the trade-wind inversion layer, the much drier and warmer westerly winds blow (Mendoca and Iwaoka, 1969). During austral summer (December to March), the ascending branch of the Hadley cell is close to Réunion Island (Badosa et al., 2013). This deep convection is characteristic of the rainy season and brings high rainfall regardless of elevation, although with larger variability in the regions above 2 $\mathrm{km}$ a.s.l. (Réchou et al., 2014). Consequently, Réchou et al. (2014) have discriminated the climate of Réunion Island into only two seasons (rainy season from November to April and dry season from May to October).

\section{3 | DATA AND METHODS}

\section{1 | Data at oceanic basin and island scales}

Rainfall data ( $R R$ as the rain rate) at island scale were available for the period 1975-2015 thanks to a large network of 54 rain-gauges covering most of the territory. The reader is referred to Réchou and Kirkwood (2015) for more details about this rain-gauge network. Moreover, it is worth noticing that the rain-gauges are not uniformly located throughout the island. In particular, there are only two rain-gauges over $2000 \mathrm{~m}$, on the windward slope, and two rain-gauges above $1500 \mathrm{~m}$ (one in the southwest and another in the northwest). Among the eight rain-gauges located between $1000 \mathrm{~m}$ and $1500 \mathrm{~m}$, three are in the northeast part and five are in the west coast. There is no information concerning $R R$ higher than
$1600 \mathrm{~m}$ in the western region. This caveat should be kept in mind when analysing the results discussed hereafter.

At the oceanic basin scale, geopotential heights $(Z)$ from the European Centre for Medium-range Weather Forecasts (ECMWF) ERA-Interim archive dataset were used to determine synoptic weather regimes. The ERA-Interim re-analysis provides daily geopotential meteorological data (in gpm) for a period ranging from 1979 to 2015 with a spatial resolution of $1^{\circ}$. Preliminary analyses led us to restrict this study to a geographic domain covering the southwest Indian Ocean basin $\left(0^{\circ}-40^{\circ} \mathrm{S}, 30^{\circ}-90^{\circ} \mathrm{E}\right)$. This domain contains 2501 grid points providing information on the spatial distribution of geopotential height levels. In order to characterize relevant weather regimes from these data, a reference pressure value $\left(P_{\text {ref }}\right)$ consistent with large-scale weather patterns is further defined from the corresponding geopotential height data $\left(Z_{-} P_{\text {ref }}\right)$. This reference pressure level is determined in relation to the position of the Trade-Wind Inversion Layer (TWIL) and its variations along a vertical profile measured at some relevant geographic point. Because the meteorological conditions on the island are strongly influenced by the (south-) easterly trade-wind regime, the TWIL was studied at a reference point located off the east coast of the island.

The reference pressure level, $P_{\text {ref }}$, should be low enough to occur above the boundary layer, and avoid the effect of the ground while taking into account clouds formed under the trade-wind inversion layer (Réchou et al., 2014). Thus, $P_{\text {ref }}$ should be high enough to not be disconnected from weather conditions while occurring under the TWIL. In the following, a height of $1 \mathrm{~km}$ represents the typical boundary-layer thickness. Consequently, $P_{\text {ref }}$ should be lower than $925 \mathrm{hPa}$. Before defining this reference level, the vertical distribution of the TWIL must be investigated.

\section{2 | Method}

\subsection{1 | Characterization of the trade-wind inversion layer}

The TWIL is the layer where the direction of the wind veers, from easterly at low altitude to westerly at higher altitude. The inversion prohibits vertical motion across layers and contributes to the stability of the vertical profile. The height of the TWIL is usually determined by the analysis of vertical profiles of temperature, humidity, mixing ratio and wind (Mendoca and Iwaoka, 1969; Cao et al., 2007). The TWIL, which separates the wet lower layer of the atmosphere from the dry upper layer, is marked by either a reversal of the temperature gradient and warming, or by a reduction of the gradient (Carrillo et al., 2016). A more classical approach defines the TWIL as the layer where relative humidity decreases rapidly (immediately above moist clouds), at about the same level where the temperature increases (Grindinger, 1992). This condition on the relative humidity is often considered as more relevant to define the position of the TWIL and is retained in this study. 
(a)
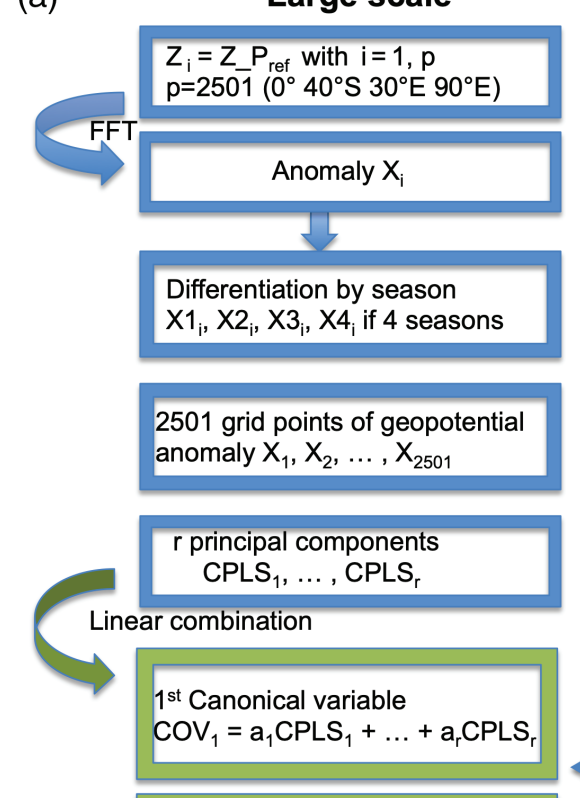

$\mathrm{n}$ independant canonical variables $\mathrm{COV}_{1}, \mathrm{COV}_{2}, \ldots, \mathrm{COV}_{\mathrm{n}}$

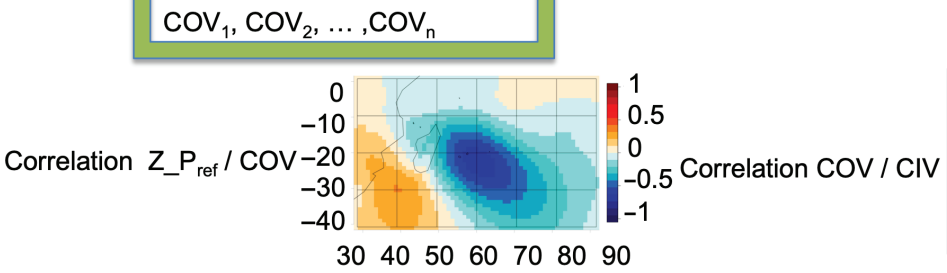

(b) Local scale

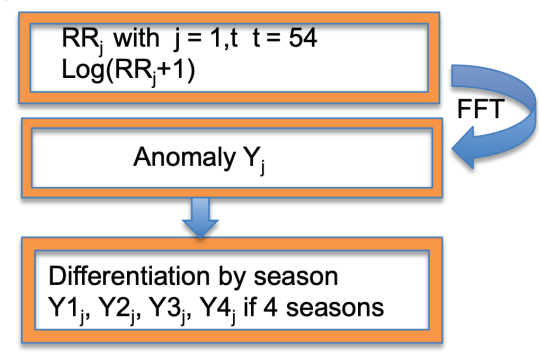

For each season

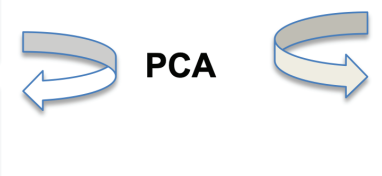

Rain anomaly from 54

Raingauges $Y_{1}, Y_{2}, \ldots, Y_{54}$

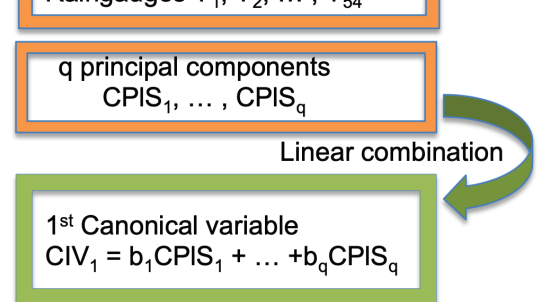

Correlation Variance $=1$

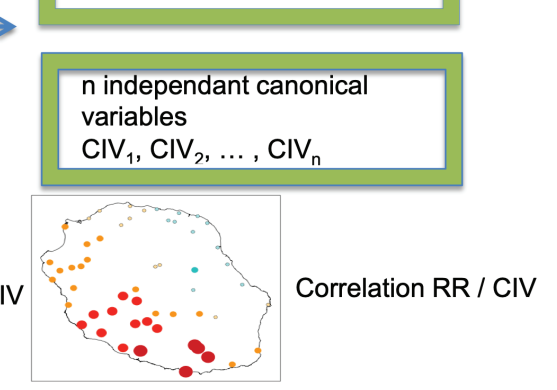

FIGURE 1 Description of the statistical analysis (PCA and CCA)

In this study, the TWIL was characterized by using relative humidity $(r)$ and zonal wind component $(u)$ data available from the ERA-Interim re-analysis dataset estimated at a reference point located east of the island $\left(21^{\circ} \mathrm{S}, 56^{\circ} \mathrm{E}\right)$. We use $u_{900}<0$ as a first criterion to detect the occurrence of easterly trade winds. Then we search for a sharp gradient in relative humidity to identify the pressure level of inversion across a profile of 10 tested levels $\left(c_{1}=600 \mathrm{hPa}\right.$ to $c_{10}=900 \mathrm{hPa}$, where $c$ indicates the pressure level). The pressure level of inversion, $c_{\mathrm{k}, \mathrm{inv}}$, is defined on a daily basis as the level for which the following condition is fulfilled:

$$
\frac{r_{i, k+2}-r_{i, k+1}}{c_{i, k+2}-c_{i, k+1}}<\frac{r_{i, k+1}-r_{i, k}}{c_{i, k+1}-c_{i, k}}
$$

where $i$ designates the focal day. Lastly, we use a condition on the value of relative humidity to constrain the identification of the TWIL: relative humidity should be higher than $65 \%$ below the altitude of the inversion level: $r_{i, k+2}>0.65$. This final condition only influences the detection of the TWIL from December to April.

\subsection{2 | Definition of seasons based on inversion regime}

Apart from defining a reference pressure level to study large-scale weather patterns, the distribution of the TWIL is also used to identify seasons with consistent local wind and inversion regimes. Based on the definition of the TWIL, a pressure inversion level corresponding to the pressure of inversion of the wind can be assigned to each day within the period of analysis (or an indication about the absence of inversion). Four categories of days were defined: one for days showing no inversion along the elevation profile, and three others with inversions occurring within the intervals 600-750, 775-825 and 850-900 $\mathrm{hPa}$, which are respectively defined as intervals of high, medium and low inversion. Using the distribution of monthly frequency of inversion events in the different categories, we eventually define seasons based on similar profiles across the year.

\subsection{3 | Statistical analyses}

The following analyses are inspired from different experiments on climate model downscaling that involve the use of weather type classifications. The different steps of the method are schematized in Figure 1. Whereas such classification often relies on a combination of principal components (PCA) from large-scale variables on one hand and local ones (here at island scale) on the other hand, the classification method utilized here makes use of canonical correlation analysis (CCA) applied to the two groups of variables. Here, the local climatology, based on rainfall distribution at island scale, is related to large-scale weather regimes identified from ECMWF geopotential height data. We analyse daily $R R$ data available for 13505 individual days and 54 rain-gauge sites. In order to lower the large variability in the measurements, 
which vary over several orders of magnitude between storm events and dry days, we log-transform rainfall data $(\log (R R+$ $1))$. At large scale, ECMWF data contain daily estimates for the 2501 grid points at oceanic basin scale.

Pre-treatment analyses are performed on both the geopotential height and the rainfall data to remove periodical components due to seasonality from the temporal series. Indeed, the geopotential height field, $Z$ at $P_{\text {ref }}\left(Z \_P_{\text {ref }}\right)$ and the rainfall pattern show strong intra-annual or seasonal variation. For example, rainfall is generally stronger in austral summer than in winter. Therefore, the influence of the seasonal variability is removed by analysing anomalies instead of raw data. To remove the seasonal variability from the two datasets, the cycle is first identified using a Fourier series decomposition. The anomalies in geopotential height and $R R$ are then produced by removing the first-order harmonic from the datasets.

The classification process for each season consists of several steps defined as follows. First, a PCA is used to identify the main axes of variation (Jolliffe, 2002) in the data at each scale. This step reduces the number of dimensions of the datasets and filters out background noise (Plaut and Simonnet, 2001). Here we filter out $5 \%$ of the total inertia which we consider as noise. Consequently we retain the first principal components of the $Z \_P_{\text {ref }}$ and $R R$ datasets that account for $95 \%$ of the total inertia. We further consider anomalies of the main axes by subtracting the average. Second, a CCA is performed to identify the major axes of covariation across the two sets of principal components. CCA aims at finding linear combinations that are maximally correlated across the two sets of variables. By construction, these linear combinations define canonical variables that are uncorrelated pairwise but show maximum correlations across datasets (Meuzelaar et al., 1992). The correlation between canonical variables decrease with their order. We designate the canonical variables identified at oceanic basin and island scale as $C O \mathrm{~V}$ and CIV respectively.

At this stage, we define the number of canonical variables used to characterize the relationships between the studied phenomena at the two scales. In order to maintain a strong enough relationship between the original data and the canonical variables as well as between canonical variables at both scales, we assess the correlations between different sets of variables and ensure that they are strong enough: $Z_{-} P_{\text {ref }} / C O V$, $R R / C I V$ and $C O V / C I V$ (see Figure 1 for criterion). Here, the first four canonical variables obtained from the CCA for each dataset showed satisfying correlations (i.e. correlation areas whose absolute value is greater than 0.5$)$, with the original data and with the canonical variables for the other dataset.

As the correlations between the $Z \_P_{\text {ref }}$ field and the different canonical variables of $C O V$ varies spatially over the studied domain, the core areas of high correlation which constitute the geographical zones with useful information for our purpose are easily identified. This information allows for a reduced spatial domain to be defined that avoids areas with noise before carrying out the classification. The PCA and $\mathrm{CCA}$ are then performed on the new domain to obtain stronger correlations. In our case, preliminary analyses lead us to limit the study domain to a spatial grid of 2501 points located in the SWIO region. In parallel, correlations between $R R$ and the $C I V$ canonical variables show which of the 54 stations display the highest correlations and are the most influenced by large-scale weather regimes (due to the correlation between $C O V$ and $C I V$ ). For instance, a centre of low pressure (in blue) located southwest of the island (Figure 1a) is generally associated with more rain in the southwest of Réunion Island than elsewhere (Figure 1b). These four canonical variables ( $C O V$ and $C I V$ ) are retained for further analyses for each identified season.

Days showing similar large canonical variables conditions (or large-scale conditions) are grouped using Hierarchical Ascending Classifications (HAC: Ward, 1963; Cheng and Wallace, 1993; Lis-Gutiérrez et al., 2018). HAC allows for defining a full hierarchy of the sampling units (here days characterized by the four large-scale canonical variables at 2501 locations) arranged in a dendrogram. The following procedure is performed for each season separately. Based on dendrogram inspection, a range of group numbers is retained as a priori numbers of different large-scale canonical variables. We then seek an optimal number of clusters (or classes) within this range using k-means (Michelangeli et al., 1995; Christiansen, 2007). The k-means method seeks to partition the observations into a number of clusters, or groups, chosen prior analysis within the range provided by the HAC. It is run from the minimum of clusters (or classes) to the maximum in order to find the optimal number within this range. The k-means partition is done on the basis of the nearest-neighbour criterion: each statistical unit, here a date, is assigned to a class if it is very close to its centroid. Classes are eventually defined as sets of units that are as close as possible.

The solution produced by the k-means may not be unique and depends on the definition of the initial centroids for the clusters. In order to evaluate the stability of the solution, we performed multiple runs $(n=30)$ based on random centroids at the start and assessed the congruence of the partitions obtained. This procedure allows for the identification of average centroids that ensure the reproducibility of the classification. When the partitions are not congruent, the procedure is repeated until reaching congruence.

Statistical diagnostics based on concordance (Lamarque and Jourdain, 1994), classifiability (Michelangeli et al., 1995) and silhouette plots (Rousseeuw, 1987) are performed to assess the quality of the classification for each a priori number of clusters (or classes), and determine the optimal number of classes for each season. We retain the optimal number of classes as the number of classes for which a minimum of no concordance (classes must be concordant), and maximum silhouette index and classifiability values are determined. More details of the technique and statistical tests are presented in the appendix. 


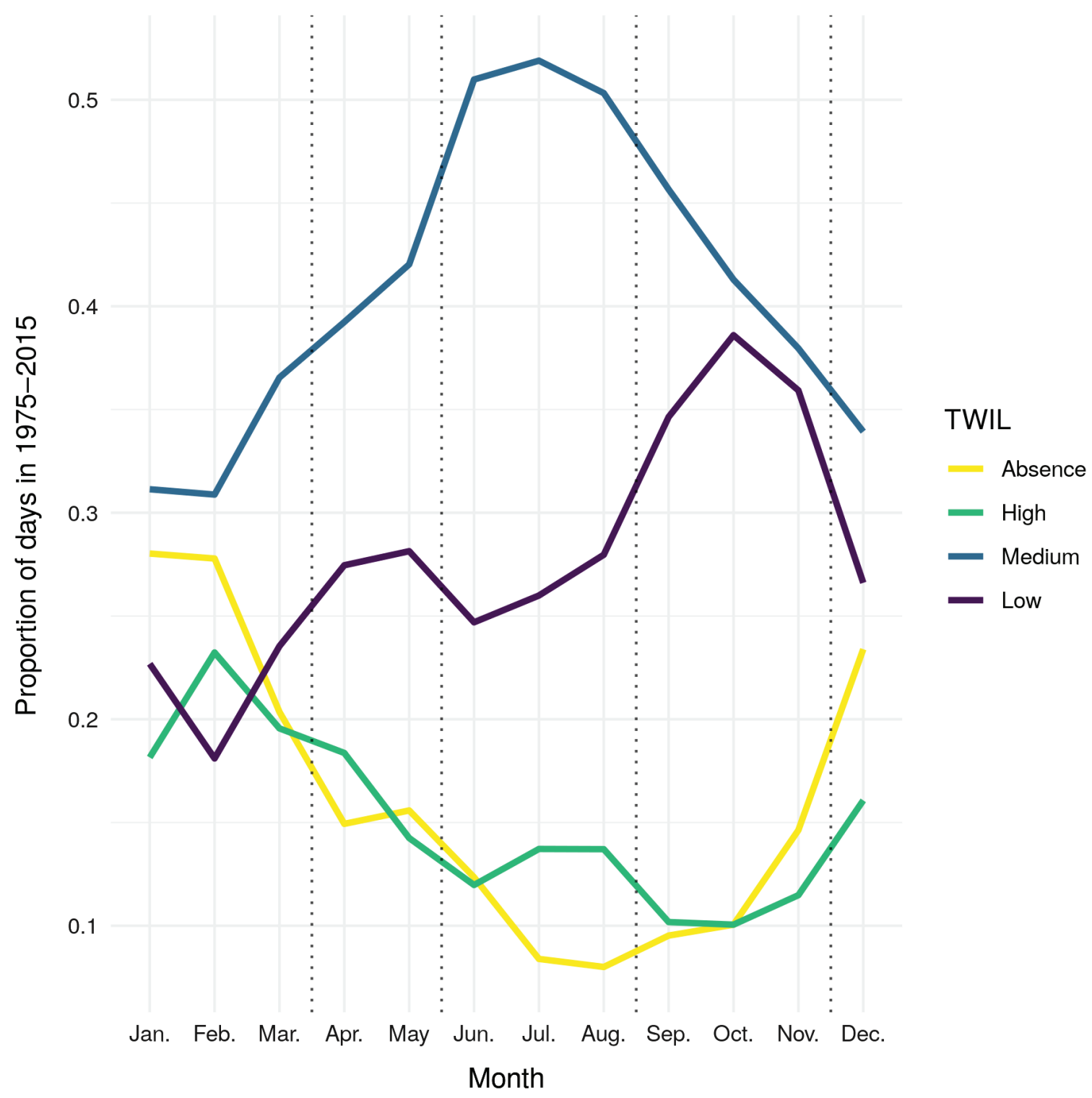

FIGURE 2 Monthly proportion of days within the period 1975-2015 classified as showing an absence of trade-wind inversion layer (TWIL), or a TWIL at various elevations above sea-level defined by pressure values: high $(600,650,700$ or $750 \mathrm{hPa})$, medium $(775,800$ or $825 \mathrm{hPa})$ or low $(850,875$ or $900 \mathrm{hPa})$

If the different tests provide two different numbers of optimal classes, $k$, this number will be characterized by visual inspection of large-scale composites maps (dates belonging to each class are given by the k-means method for a well-defined number of classes) of the composites on the $Z_{875}$ (defining weather pattern), large-scale data, and the $R R$, local scales data.

The large-scale composite maps of geopotential height allow for the description of the different weather regimes such as strong trade winds, polar fronts, or others.

For each season, the same procedure is repeated until the large-scale weather regimes are defined. Rainfall data are then analysed to characterize spatio-temporal patterns at island scale. These classes are further used on island-scale rainfall with respect to weather regimes. This approach allows defining a climatology of rainfall such that each day of the studied period (1979-2015) is assigned a particular class based on large-scale patterns.

\section{4 | RESULTS}

\section{1 | Seasons based on inversion profiles}

As shown by the monthly distribution of inversion levels (Figure 2), days without inversion account for more than $20 \%$ from December to March and less than 10\% in July and August, with transitions in between those two periods. High-level inversion events mostly occur from December to April (between 16 and 23\%) and decrease to a period of minimal values from September to November (around 10\%). Inversion events at medium elevation are the most frequent from June to August, over 30\% each month, but with a period of maximal values above 50\%, and decrease to around $30 \%$ during austral summer. By contrast, lower inversions show two periods with relatively high frequency, from September to November (above 35\%) and April to May (around 27\%), in between periods of relatively low frequency from December to March, and from June to August. 
Four main seasons that are characterized by contrasting wind regimes and rainfall are defined from the climatological patterns (Figure 2). The first season, referred to as the austral summer, runs from December to March (DJFM). DJFM corresponds to the period when inversion events at lower levels are less frequent than during the rest of the year, and when the absence of the inversion occurs with maximal frequency over the year. Interestingly, the number of days with high inversion is also important during DJFM and can reach up to $20 \%$. The second season, which extends from April to May (AM), is characterized by some variability in the inversion regime, with the inversion at lower elevations being the most frequent (around 25\%), but with intermediate frequencies of inversion in the other elevation classes. The third season, called austral winter, extends from June to August (JJA). During this period, the medium inversion levels are relatively frequent, in contrast with days of lower inversion levels or without inversion. The fourth and last season runs from September to November (SON). It shows the highest frequency of days with inversion at the lowest levels (around 35\%). Meanwhile, days of higher inversions are uncommon and fewer days show inversion at high elevation. For brevity, these four seasons will also be referred to as Summer (DJFM), Fall (AM), Winter (JJA) and Spring (SON).

\section{2 | Description of synoptic-scale weather patterns}

In order to characterize the large-scale weather regimes, we define a relevant geopotential height at a pressure level taken as a reference below which a large majority of inversion events could be reliably detected. In relation with the typical variation of the TWIL height distribution (Figure 2), the $875 \mathrm{hPa}$ level was defined as the reference pressure.

Multivariate analysis of large-scale data, $Z_{875}$, based on the 2501 grid points allowed us to discriminate classes of days with similar weather regimes at oceanic scale for each season analysed separately. Four different weather regimes are also identified for Winter and Spring. During austral summer (Summer), which shows the highest heterogeneity in the geopotential height field at $Z_{875} \mathrm{gpm}$, six different regimes are identified. The different classes are presented at $Z_{875}$ on Figure 3 with the island-scale rainfall patterns associated with similar large-scale weather regimes.

Even if class 1 is associated with Strong Easterly Trade Wind (StETW), the geopotential height field at $875 \mathrm{hPa}$ is slightly different from one season to another. It is the same for North-Western Edge Ridge (NWER) from September to March and Southerly Trough (ST) from April to November (the geopotential height fields are different from one season to another). Moreover, class 4 and 5 are composed

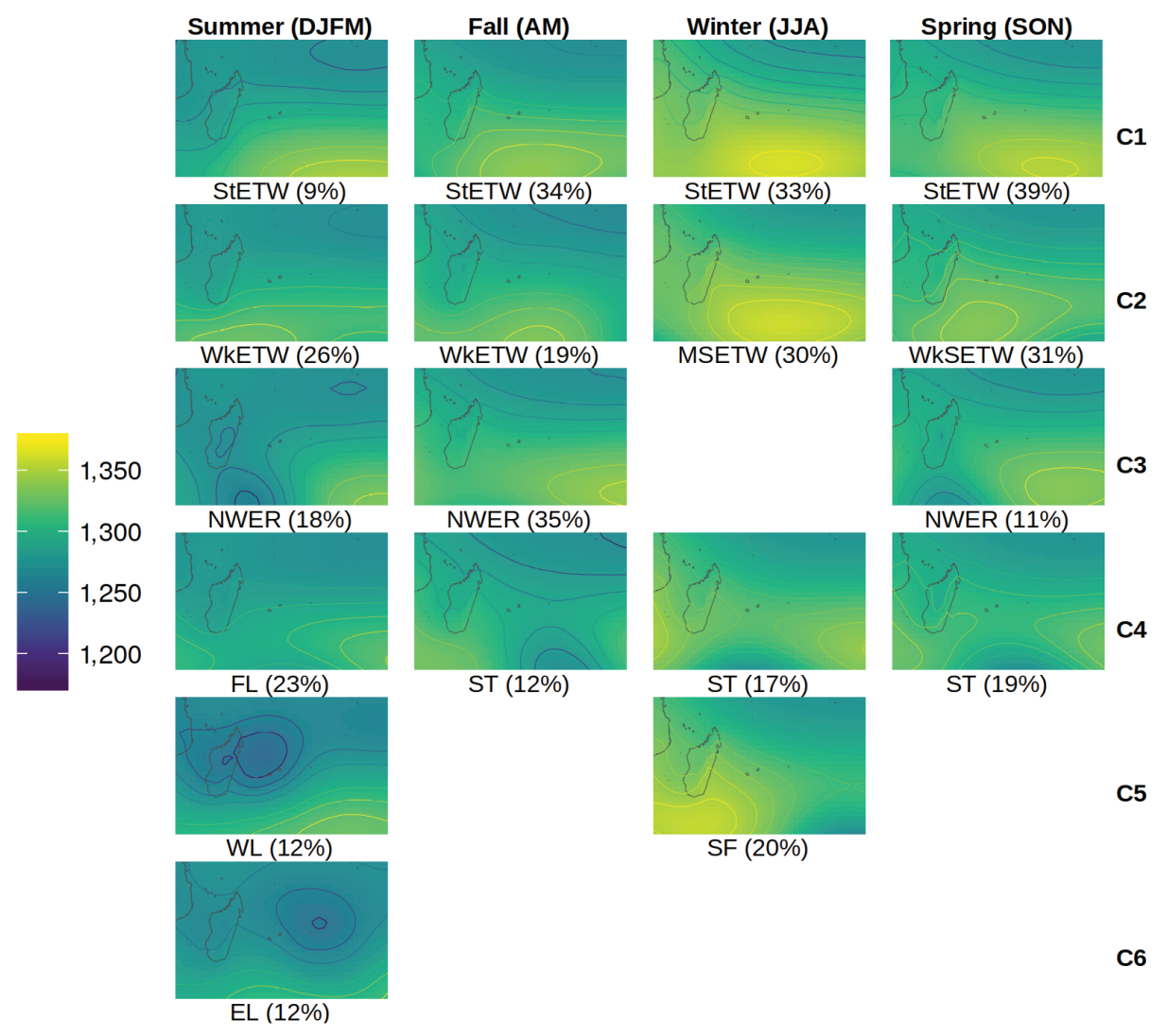

FIGURE 3 Composite maps of $875 \mathrm{hPa}$ geopotential height (gpm) for the different large-scale weather regimes. Réunion Island appears as a black dot. Relative occurrence of days within classes of similar large-scale weather regimes in four seasons (labelled by the initials of the corresponding months). Regimes were named after visual examination of large-scale composite maps: Strong Easterly Trade Winds (StETW), Weak Easterly Trade Winds (WkETW), Moderate South-Easterly Trade Winds (MSETW), Southerly Trough (ST), North-Western Edge Ridge (NWER), Southerly Flow (SF), Eastern Low (EL), Western Low (WL), Flat Low (FL). Numbers indicates the proportion of days within each season that correspond to the weather classes (\% over the 37-year period). 
of different weather patterns. Class 6 was only found in Summer.

These different temporal patterns of synoptic weather regimes can be related to the position of the intertropical convergence zone (ITCZ) (Hu et al., 2007), which in turn influences the location of the Mascareigne Anticyclone throughout the year. When the anticyclone is strong (at least $1025 \mathrm{hPa}$ : Le Borgne, 1987) and located southeast of the island, winds tend to strengthen (around $16 \mathrm{knots}(1 \mathrm{kn}=0.514 \mathrm{~m} / \mathrm{s}))$ to produce strong trade winds. These trade winds become weaker when the pressure gradient decreases, which occurs when the anticyclone either collapses, moves eastward, or when a westerly low-pressure system comes nearby. The strong wind regime is then replaced by moderate/weak trade winds. This type of weather is accompanied by a barometric drop and reduced lower wind speeds (<13 knots) (Barcelo and Coudray, 1996). This pattern is used to discriminate StETW from Weak Easterly Trade Wind (WkETW). Weak and moderate trade winds change from an easterly direction in summer and autumn, to southeasterly during winter and spring.

In this work, the WkETW are associated with an anticyclone of $Z_{875}<1330 \mathrm{gpm}$, StETW are associated with an anticyclone of $Z_{875}>1360 \mathrm{gpm}$ and Moderate South-Easterly Trade Wind (MSETW) to an anticyclone of $Z_{875}$ around 1330-1360 gpm. However, these values can slightly change (less than 10\%) with the season (as already mentioned above).

During Summer, when the ITCZ is close to Réunion Island, the atmosphere is warm and moist. Lower-pressure periods are more frequent and can be separated into two classes, the West Low (WL) and East Low (EL). A particular neutral class also appears (Flat Low, FL) that consists of a barometric saddle point where local circulations such as breeze phenomena prevail. During this season, high oceanic pressure from the east is infrequent. Thus, StETW are rare with only $9 \%$ of days being associated with this weather regime (compared with more than $33 \%$ during the rest of the year). When present, the anticyclone is generally weak, leading to weak TW. All these weather regimes increased the number of no and high inversion cases during that season.

During Fall, as the ITCZ moves northward, the anticyclone strengthens and regimes of low atmospheric pressure do not occur any more. As a consequence, StETW days, as well as NWER, are more frequent, and conditions typical of the Southerly Trough (ST, similar to the temperate tropical trough which affects rain in southern Africa: Vigaud et al., 2012) appear.

During Winter, generally considered as the winter season, the ITCZ is pushed further north. Consequently, this season is associated with strong (moderate) anticyclones, located in the east (southeast) of Réunion Island, leading to more frequent StETW (MSETW) weather regimes. Moreover, Southerly Flux (SF) conditions appear (20\%) and ST frequency increases (from $12 \%$ in Fall to $17 \%$ ), which leads a total of $37 \%$ of southerly perturbations during that season. These regimes are responsible for the high frequency of days with low inversions and low frequency of days without inversion during that season.

During Spring, trade wind conditions prevail with a $70 \%$ frequency (39\% frequency of StETW and $31 \%$ of Weak South-Easterly Trade Wind, denoted WkSETW). Spring WkSETW replace the Winter MSETW because the ITCZ is closer to Réunion Island. For the same reason, SF are prevented from developing and conditions of NWER begin to appear. This class is associated with few winds and few trade winds with flux from north/northeast. Note that this NWER class is absent during winter when the anticyclone is strong and closer to Réunion Island. With respect to Summer, the Spring ITCZ is slightly further north, which allows ST situations (19\%). This regime explains the high frequency of lowest inversion; numerous cases of anticyclones lead to stronger subsidence.

\section{3 | Rainfall variability}

Rain rates measured by the 54 rain-gauges over the 37 -year study period for each season are shown in Figure 4, as a function of both weather regimes (Tables 1 and 2) and elevation/azimuth of each rain-gauge (Figures 5-8). The azimuth is relative to the summit of the Piton des Neiges, which is the highest mountain peak $\left(3070 \mathrm{~m}, 21^{\circ} 05^{\prime} 56^{\prime \prime} \mathrm{S}\right.$, $\left.55^{\circ} 28^{\prime} 44^{\prime \prime} \mathrm{E}\right), 0^{\circ}$ indicating north $(\mathrm{N})$ and $90^{\circ}$ east $(\mathrm{E})$.

\subsection{1 | Seasonal rain patterns}

Table 1 presents the mean average of daily rainfall, standard deviation per season and per station (rain-gauge) over the study period, as well as the maximum observed daily rainfall. Figure 4 presents the geographical distribution of mean daily rainfall for each season.

At island scale (Table 1), rainfall mainly takes place during summer (seasonal average is $11.5 \mathrm{~mm} /$ day) and decreases through the year to its minimum in Spring $(2.7 \mathrm{~mm} /$ day $)$. The proximity of the ITCZ to Réunion Island during Summer makes the atmosphere warm and moist. Summer is also the tropical cyclone season (19 cyclones passed within $300 \mathrm{~km}$ of the island during that period bringing maximum amounts of precipitation). One cyclone was associated with a maximum of $1760 \mathrm{~mm} /$ day measured by some rain-gauges. The maximum rainfall variability is reached during Summer ( $40 \mathrm{~mm} /$ day), which can be explained by the occasional passage of cyclones and tropical storms. The driest season (Spring) is also the season showing the minimum daily rainfall variability $(11 \mathrm{~mm} /$ day $)$.

A strong east/west (E/W) asymmetry exists across the transect from Saint Joseph to Sainte Marie (Figure 4). During Fall, the E/W asymmetry is even stronger. During Winter, the north-northwest coast of the island is extremely dry with less than $1 \mathrm{~mm}$ of rain per day, while more than $7 \mathrm{~mm} /$ day can be reached in the south-southeast part of Réunion Island. Finally, during Spring, the orographic rain gradient is less 


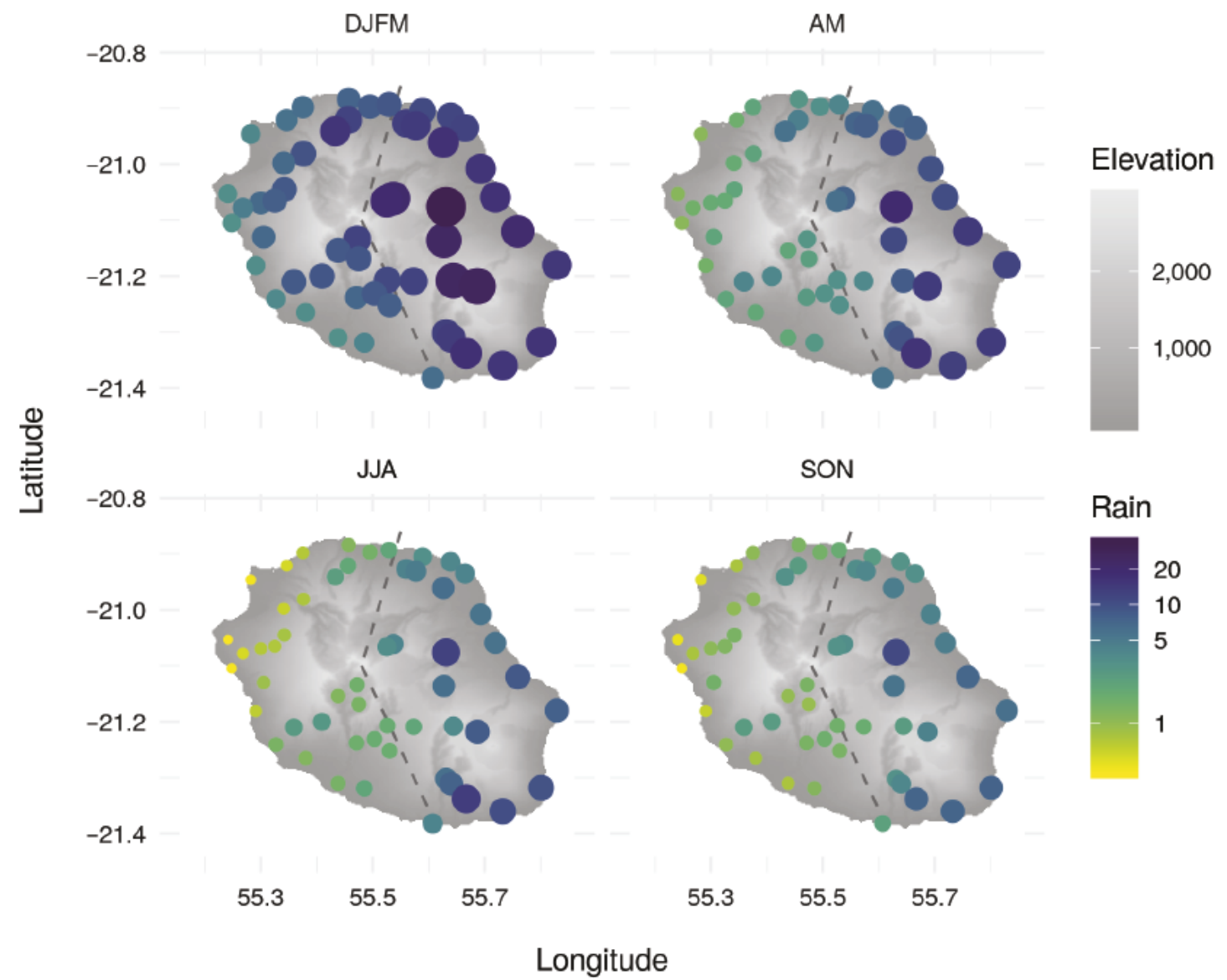

FIGURE 4 Distribution of mean daily rainfall (mm/day) at island scale in four seasons (Summer, Fall, Winter, Spring)

TABLE 1 Mean average of daily rainfall, standard deviation per season and per station (rain gauge) over the study period, as well as the maximum observed daily rainfall

\begin{tabular}{llll}
\hline Season & Mean & SD & Max \\
\hline DJFM & 11.5 & 40 & 1,760 \\
\hline AM & 5.8 & 19 & 696 \\
\hline JJA & 3.5 & 12 & 637 \\
\hline SON & 2.7 & 11 & 424 \\
\hline
\end{tabular}

Note. Max: maximum observed daily rainfall; SD: standard deviation.

marked: stations located to the south and east in the lowland show more precipitation than those located at higher elevation. This season is drier than winter although the ITCZ is closer to Réunion Island.

\subsubsection{Relationships between rainfall patterns and synoptic weather regimes}

Except for Summer, when WL conditions bring maximal rainfall (Table 2, a maximum up to $1760 \mathrm{~mm} /$ day), high rainfall amounts are associated with the occurrence of TW. Classes other than TW and WL, i.e. NWER, EL, FL, SF and ST, are associated with lower rainfall (Table 2). The different conditions of low atmospheric pressure (WL, FL and EL) at large scale bring different amounts of rainfall. As seen before, rainfall is higher when Western Low conditions occur during Summer, which makes that season very rainy on average even if this class is not frequent. It is associated with storms more or less intense (among the 28 days of cyclones mentioned earlier, 25 belongs to WL, 2 belong to WkETW and 1 to FL), whose intensities are highly variable (standard deviation of rain for this class of $99 \mathrm{~mm} /$ day for some rain-gauges). In contrast to the WL regime (mean average by station of daily mean of $47 \mathrm{~mm} /$ day), $\mathrm{FL}$ and $\mathrm{EL}$ conditions bring weaker rainfall (with the least important maxima during Summer: 5.9 and $5.7 \mathrm{~mm} /$ day respectively) (Table 2 ). The weak rain associated with $\mathrm{FL}$ is not surprising since this weather pattern is considered as a neutral class.

Rain brought by the TW is more important during Summer (an average of $9.5 \mathrm{~mm} /$ day, two cyclones travel within less than $300 \mathrm{~km}$ of Réunion Island) and Fall $(7.8 \mathrm{~mm} /$ day $)$, than during Winter $(4.2 \mathrm{~mm} /$ day $)$ and Spring $(2.8 \mathrm{~mm} /$ day $)$. In NWER conditions, the rain associated with this class is more important during Summer $(9.1 \mathrm{~mm} /$ day $)$ than Fall $(5.1 \mathrm{~mm} /$ day) and Spring $(2.2 \mathrm{~mm} /$ day $)$. During ST regimes, rainfall associated with this class is more important during Fall $(4.2 \mathrm{~mm} /$ day $)$ than Winter $(3.3 \mathrm{~mm} /$ day $)$ and Spring $(2.9 \mathrm{~mm} /$ day $)$. This is due to the humidity of the atmosphere on the island. As mentioned before, the proximity of the ITCZ brings large amount of humidity over the island, except for Spring which is the drier season. During Winter, when the ITCZ is away from Réunion Island, southern perturbations (SF, 20\%) bring rain (and humidity), which is not the case for Spring. 
TABLE 2 Mean average of daily rainfall, standard deviation per season, per class of large weather regimes and per station (rain gauge) over the study period, as well as the maximum observed daily rainfall

\begin{tabular}{|lllllllll} 
Season & Variable & C1 & C2 & C3 & C4 & C5 & C6 \\
\hline DJFM & Mean & 7.8 & 9.5 & 9.1 & 5.9 & 47.0 & 5.7 \\
\hline DJFM & SD & 22.2 & 28.6 & 31.9 & 18.8 & 99.0 & 17.8 \\
\hline DJFM & Max & 650.0 & 700.0 & 1173.0 & 560.0 & 1760.0 & 388.5 \\
\hline AM & Mean & 5.8 & 7.8 & 5.1 & 4.2 & NA & NA \\
\hline AM & SD & 19.0 & 23.2 & 18.5 & 13.7 & NA & NA \\
\hline AM & Max & 535.0 & 482.0 & 696.0 & 418.0 & NA & NA \\
\hline JJA & Mean & 4.2 & 3.1 & NA & 3.3 & 3.0 & NA \\
\hline JA & SD & 14.4 & 10.4 & NA & 11.9 & 11.0 & NA \\
\hline JA & Max & 637.0 & 326.5 & NA & 337.0 & 282.0 & NA \\
\hline SON & Mean & 2.8 & 2.8 & 2.2 & 2.9 & NA & NA \\
\hline SON & SD & 9.9 & 11.6 & 8.6 & 10.9 & NA & NA \\
\hline SON & Max & 424.1 & 377.0 & 240.0 & 270.0 & NA & NA \\
\hline
\end{tabular}

Note. Max: maximum observed daily rainfall; SD: standard deviation.

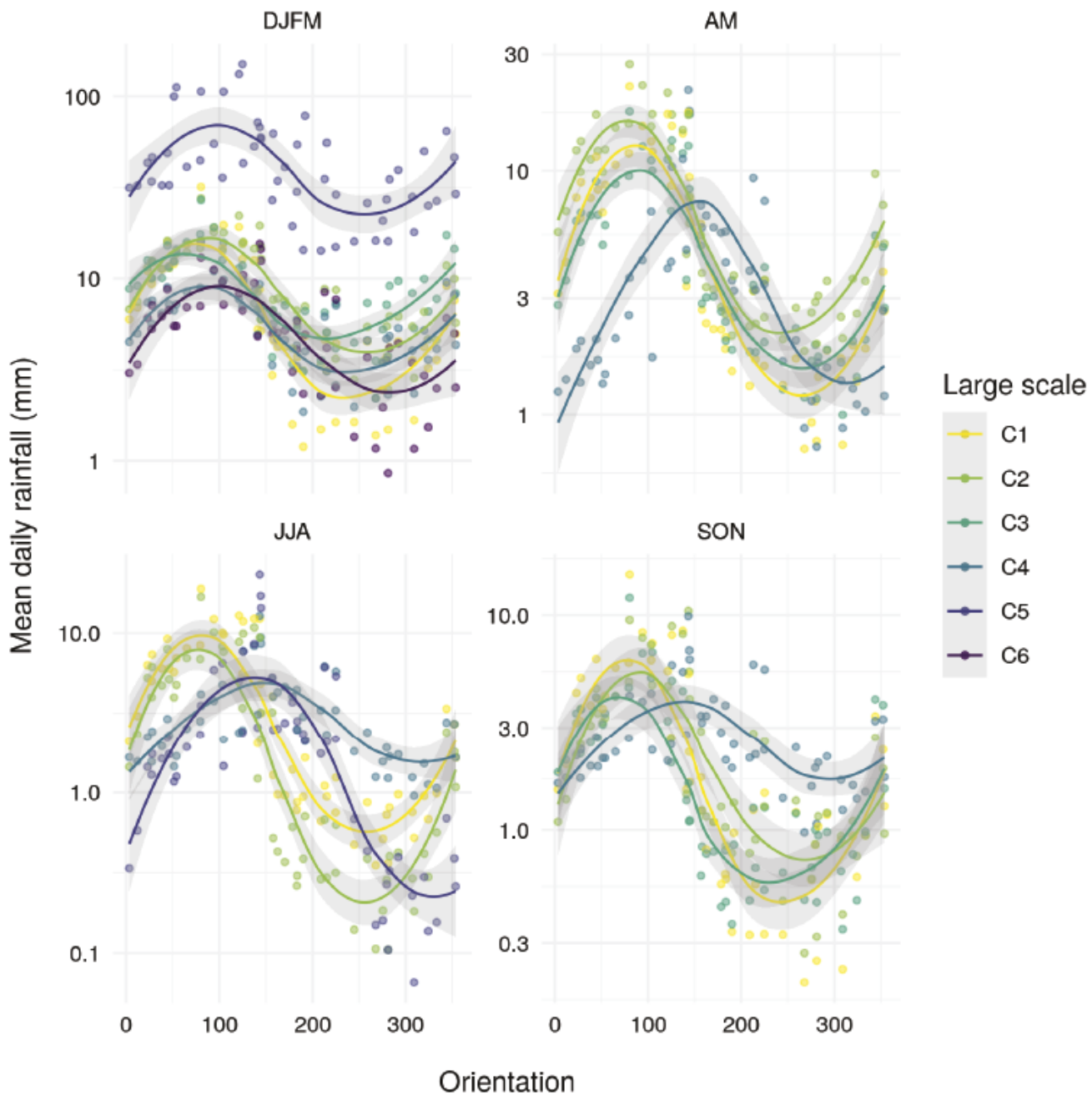

FIGURE 5 Relationships between mean daily rainfall ( $\mathrm{mm} /$ day) and orientation for the four studied seasons (Summer, Fall, Winter, Spring), and the different classes of large-scale weather regimes (C1-C6)

\subsection{3 | Rain as a function of azimuth}

Figure 5 presents the relationships between mean daily rainfall and orientation for the four studied seasons together with the class of large-scale weather regimes. For all seasons, the mean daily rainfall varies sinusoidally with azimuth. For most weather patterns that were characterized, an E/W asymmetry was observed with a maximum value in the east $\left(90^{\circ}\right)$ or southeast, and a minimum value to the west $\left(\mathrm{ca} .250^{\circ}\right)$. The relief of the island contributes to create "leeward" and "windward" conditions according to the sector of the dominant 


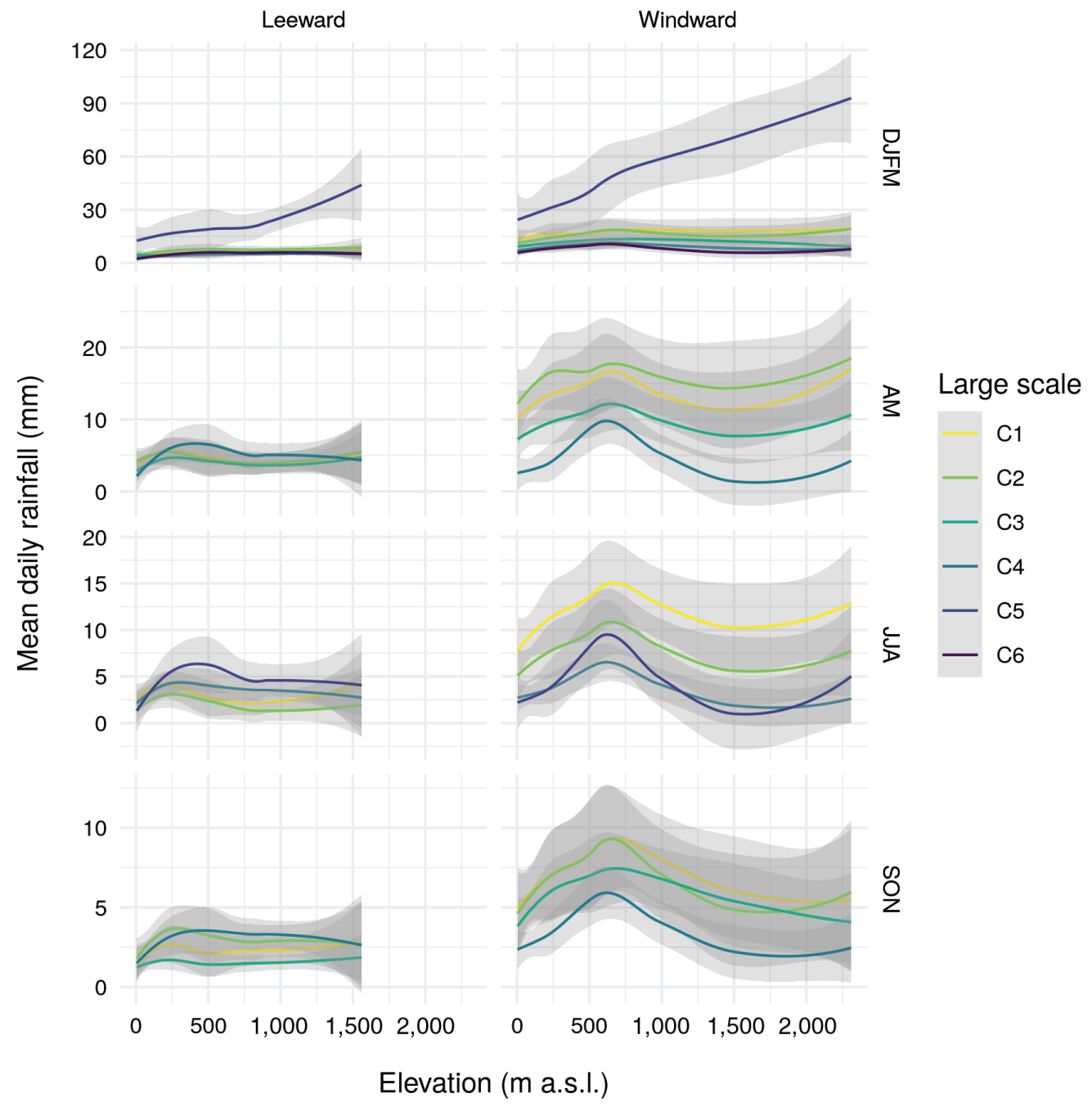

FIGURE 6 Relationships between mean daily rainfall (mm/day) and elevation (m) for the four studied seasons, and the different classes of large-scale weather regimes (C1-C6). Note the different scales on the $y$-axes. Elevation range of rain-gauges varied between the leeward and windward side of the island ( $x$-axis)

stream. The flow, often from the east or southeast, brings moist air and, as this air rises over the island, it cools, the moisture condenses and generates rainfall; so, in the west part, the air is drier as the moisture has been lost as it rises in the east part. This process occurs for all the cases that include a strong component of the trade wind. All such regimes bring moist air towards the east and the maximum of precipitation associated with the TW (strong, weak or moderate TW) is located from $80^{\circ}$ to $100^{\circ}$. The minimum value location is between $220^{\circ}$ and $260^{\circ}$. Surprisingly, TW extrema are at the same location whether they are located in the east or southeast (MSETW, WkSETW). This result is in agreement with Barcelo and Coudray (1996) who found that rainfall associated with TW presents a strong E/W asymmetry along the St Joseph/St Marie transect. For EL and FL the minima are also between $270^{\circ}$ and $230^{\circ}$ respectively.

Nevertheless, all the weather regimes are not associated with easterly flow: SF and ST classes are associated with southerly flux, and the NWER class is associated with northeasterly flux of variable intensity.

Perturbations from the south generate important amounts of rain in the south-southeast (maximum at around $150^{\circ}$ ), while the northwest quarter remains almost dry (daily rainfall $<1 \mathrm{~mm}$, minimum at around $320^{\circ}$ ) since the flow does not affect the north-northeast; this introduces a northwest/southeast asymmetry of rainfall (during the Winter and Fall seasons). ST is a large class with, for example, cold fronts. Different cases of ST not only bring rain in the south but more or less in the southeast. For example, in the lee of the cold front (or right after), the southeast of the island will experience even more precipitation.

Finally, NWER corresponds to the end of the ridge with a weak northeast flux (maximum of rain around $60^{\circ}$ ) making the south of the island drier compared to other classes (asymmetry northeast/southwest). This is clearer for Summer where the minimum of rain obtained in that class is at around $210^{\circ}$, less for Spring where the minimum is around $220^{\circ}$, and even less for Fall with a minimum located around $250^{\circ}$.

Regarding the relationship between the variability of rain with orientation (Figure 5), the WL class shows a larger variation range (more than $30 \mathrm{~mm} /$ day) than the TW classes in summer (around $10 \mathrm{~mm} /$ day). Such amplitude is more important than for NWER conditions, and even more than for EL and FL. Due to their characteristics (weak low far away from 


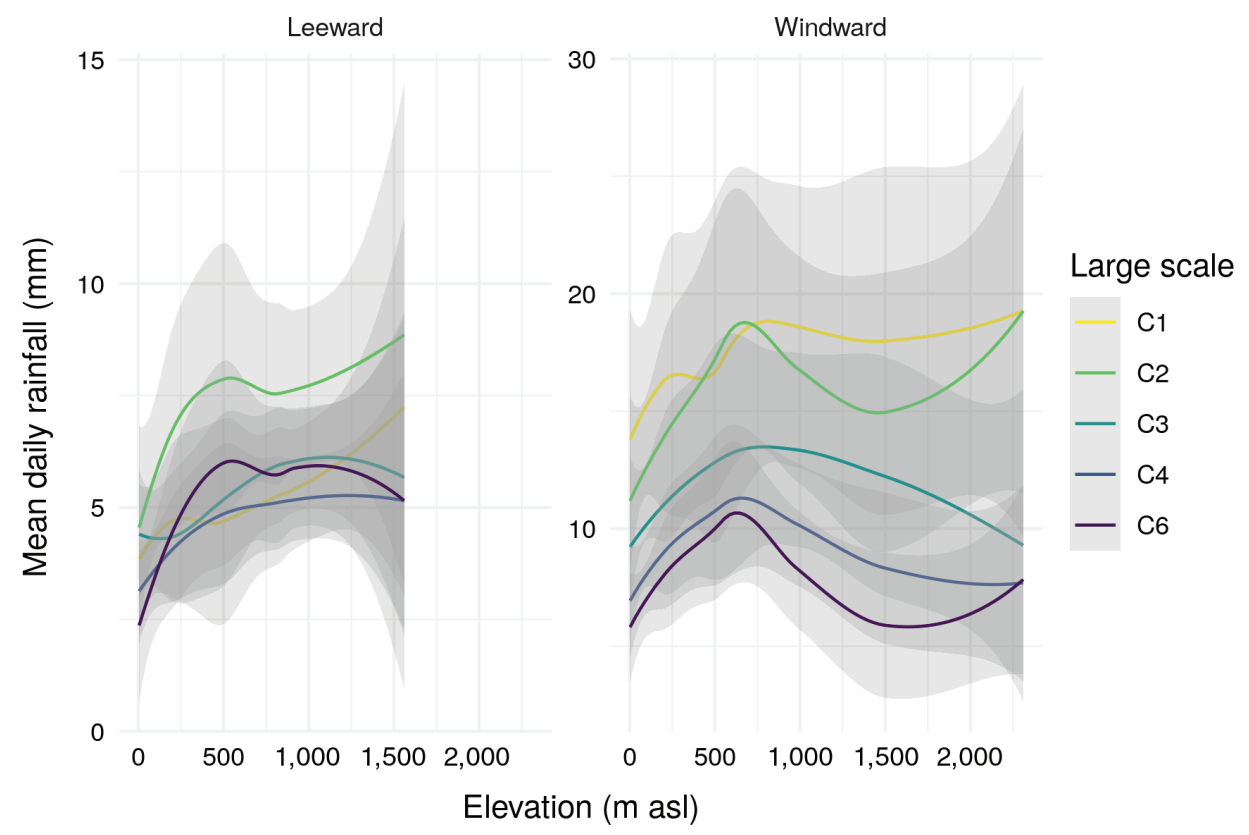

FIGURE 7 Relationships between mean daily rainfall ( $\mathrm{mm} /$ day) and elevation $(\mathrm{m})$ for the Summer season (DJFM), without class C5. Note the different scales on the $y$-axis. Elevation range of rain-gauges varied between the leeward and windward side of the island ( $x$-axis)

Réunion Island in the first case and a neutral situation in the second case), these last two classes are associated with less precipitation and consequently less variation in amplitude, but more than SF and ST's ones (since there is more humidity during Summer, and SF and ST are not present then). Rainfall associated with SF during Winter presents a stronger amplitude variation than that associated with ST. In fact, during the ST weather regime, fronts reaching tropical latitudes often occur in an attenuated form, but bring cloudy weather and low-to-moderate rainfall so the amplitude variation of the rain associated with that class is weak.

For the NWER weather regime, the azimuthal variation of rain decreases from Summer to Fall, and from Fall to Spring. For the ST regime, the azimuthal variation decreases from Fall to Spring. For the TW regime, the azimuthal variation decreases from Summer to Spring.

Finally, note that rain under TW depends on the humidity in the atmosphere on the island and does not seem to depend on the intensity of the trade winds (weak/moderate and strong trade winds); sometimes there is more rain with StETW, at other times with the WkETW regime.

\subsection{4 | Rain as a function of elevation}

In order to study the rain distribution as a function of the elevation, Figures 6 and 7 present the relationships between mean daily rainfall and elevation for the four studied seasons and the different classes of large-scale weather regimes. Figure 7 is the same representation for all the classes except WL during Summer. To finish, Figure 8 presents the distribution of mean daily rainfall at island scale during four seasons and different classes of large-scale weather regimes.

Associated with WL conditions during austral summer (Summer), rainfall varies strongly with elevation. Tropical depressions produce very intense rainfall up to the summits; the orographic gradient is strongly marked. The gradient of precipitation with altitude is stronger windward than leeward: rainfall attains nearly $95 \mathrm{~mm} /$ day and nearly $45 \mathrm{~mm} /$ day, respectively (Figure 6). Moreover, that gradient is stronger above $500 \mathrm{~m}$ windward and $1000 \mathrm{~m}$ leeward. These atmospheric situations are marked by very strong daily rainfall gradients dependent on the altitude on both sides of the island; rainfall gradient is around $10 \mathrm{~mm} / 150 \mathrm{~m}$ above $1000 \mathrm{~m}$ leeward; WL provide the highest monthly radar quantitative precipitation estimation (QPE) during the summer months. This is due to the strong humidity in the whole troposphere during storms. In comparison, the orographic effect in trade-wind mode (StETW and WkETW) leads to daily average gradients on the order of $2 \mathrm{~mm} / 100 \mathrm{~m}$ of altitude to the most watered zone (Barcelo and Coudray, 1996) up to $650 \mathrm{~m}$.

Considering all classes except WL (Figures 6 and 7), the maximum of mean daily rainfall is reached at $650 \mathrm{~m}$ during all the seasons along the windward slopes. On the leeward side, the relationship between rainfall and elevation is more complex. High heterogeneity of rain likely results from the interaction of meteorological conditions implied by large-scale weather regimes and local phenomena such as orographic and thermal breezes. For all the classes of weather in which atmospheric flow is from the east, there is a maximum of rain at $250 \mathrm{~m}$ leeward (in the west part of the island) from April to November. During Summer, as the atmosphere is hotter and more humid, ascending motions are higher leeward and rainfall stronger than during the other seasons.

For classes in which atmospheric flow is from the south (ST, SF) or northeast (NWER), the precipitation leeward reaches higher altitudes than $250 \mathrm{~m}$ since the atmospheric disturbance associated with those classes affects the west as the east part. 


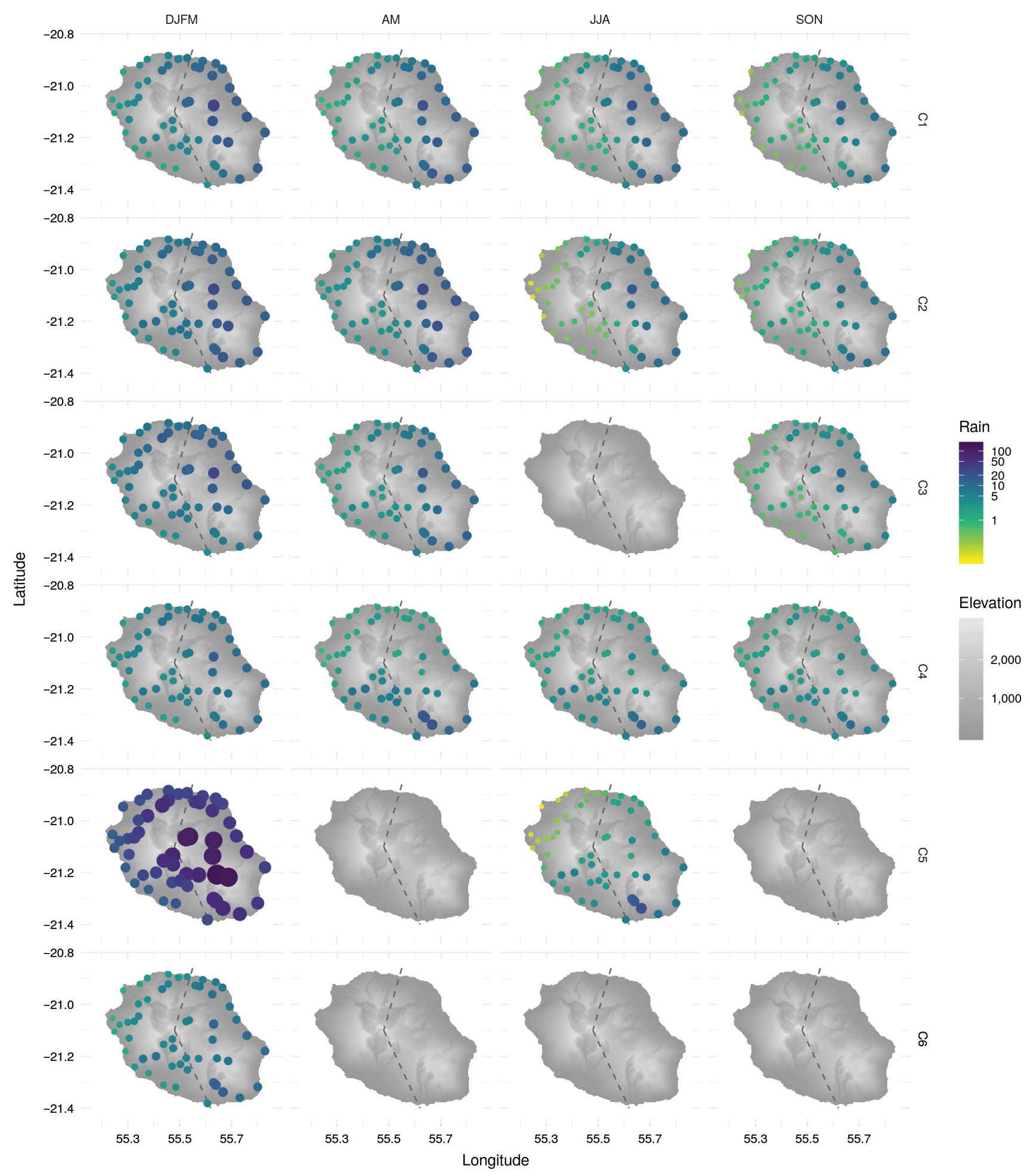

FIGURE 8 Distribution of mean daily rainfall (mm/day) at island scale during four seasons (Summer, Fall, Winter, Spring) and different classes of large-scale weather regimes (C1-C6)

Windward, the ST class is associated with less rain at high elevation compared to low elevation during Fall, Winter and Spring. NWER and StETW also present less rain in the upper part than over lower ground during Spring. Since NWER, StETW and ST represent 69\% during Spring and are associated with significant rain during that season, an inversion of the rainfall gradient is observed with altitude. Such a result is in agreement with Barcelo (1996) which stipulates that a high proportion of south disturbance rainfall and low circulation systems can cause inverted rain gradients during that season, especially in October and November. Finally, for both leeward and windward regions, the variation in amplitude of rain with respect to altitude decreases from Summer (up to 50 and $80 \mathrm{~mm} /$ day, respectively) to Spring (down to 5 and $10 \mathrm{~mm} /$ day, respectively). This result should be put in context of the humidity in the atmosphere and the 
height of the TWIL: both decrease from Summer to Spring. This can be explained by the fact that the TWIL limits the vertical development of clouds.

\section{5 | DISCUSSION}

Spatio-temporal rainfall patterns over Réunion Island vary strongly in relation with large-scale weather regimes in the southwestern Indian Ocean. First, the determination of the TWIL was realised every day with the vertical profile of $u$ and $r$ in the east of the island. Patterns of inversion height are comparable with those documented in Hawaii's archipelago, that is nearly symmetric in the Northern Hemisphere regarding latitude compared to Réunion Island. Using radiosonde data available for the 1979-2003 period, Cao et al. (2007) found a low frequency of their "no-inversion" class from May to August (around 10\%) and high frequency between September to April (around $20 \%$ ) in Hilo $\left(19.72^{\circ} \mathrm{N}, 155.05^{\circ} \mathrm{W}\right)$. In Lihue $\left(21.97^{\circ} \mathrm{N}, 159.33^{\circ} \mathrm{W}\right)$, days without inversions were around $15 \%$ from April to August, more frequent from September to November (more than 20\%) and around 18\% from December to March. Average frequencies of cases without inversion are therefore similar across the two geographic situations, although their detailed distribution is opposite, i.e. in the Northern Hemisphere, days without inversion are important during autumn and winter in Lihue, although in Réunion Island (Southern Hemisphere) days without inversion are more frequent during Summer. Moreover, the mean inversion pressure level in Réunion Island was found around $813 \mathrm{hPa}$, although Cao et al. (2007) found average base heights of $2225 \mathrm{~m}(781.9 \mathrm{hPa})$ for Hilo and $2076 \mathrm{~m}(798.8 \mathrm{hPa})$ for Lihue. Grindinger (1992) and Tran (1995) found mean inversion base heights 2322 and $2405 \mathrm{~m}$ in Hilo respectively. As pointed out by Cao et al. (2007), the results may depend on the length of the time period analysed and the analysed data.

The variation of pressure of TWIL over the year allowed us to identify four main seasons characterized by different atmospheric circulation regimes in Réunion Island.

The canonical correlation analysis between local rainfall data and the $875 \mathrm{hPa}$ geopotential height field also allowed for the definition of different large-scale classes of weather pattern occurring within each season. The orography of the island was also found to dramatically impact rainfall distribution according to the direction of main inflow. While heavy rainfall is frequent over the windward area (with up to $12 \mathrm{~m} /$ year of rain on average), the other part of the island is excessively dry (with less than $1 \mathrm{~m} /$ year). As a consequence, the föehn effect was also found to occur often over the leeward area. This leads to warmer temperatures and a reinforcement of the drier conditions.

During Summer, in the large WL weather class, the proximity of the ITCZ to Réunion Island leads to strong storms and cyclones, which produce a majority of the rain during that season. Even if WL is not frequent during summer, the orographic gradient of rain due to strong humidity over the troposphere during WL is well observed in summer overall. Whereas FL and EL situations account for $35 \%$ in total during summer, they are associated with a low amount of rain with respect to cyclones and storms.

Windward, except for WL classes, the maximum of rainfall is around $650 \mathrm{~m}$ a.s.l. Leeward, for all the classes for which the flow is easterly, it is around $250 \mathrm{~m}$ from April to November and higher (between 500 and $1000 \mathrm{~m}$ ) during Summer when the atmosphere is hotter and moister. By Leeward, for all the classes for which the flow is not easterly, the maximum of rainfall is around $350 \mathrm{~m}$ from April to November and higher for Summer.

During Fall, as the ITCZ moves further north, the Mascareigne anticyclone is deeper than during Summer. That situation leads to more StETW and less WkETW. Moreover, the E/W asymmetry shown by the rainfall distribution is the strongest during that season. Given that ST, StETW, WkETW and NWER are the weather patterns identified for that season, this result can be explained by the fact that, compared to ST situations, TW and NWER situations account for $88 \%$, show respectively a stronger east/west and east-northeast/west-southwest asymmetry in the rainfall distribution, and bring more rain.

During Winter, as the ITCZ moves further north, the strength of the anticyclone increases again, which corresponds to the season of strong trade winds. Moreover, perturbations from the south are numerous, with more frequent ST and SF weather patterns (37\% in total). These last two weather patterns are associated with a south-southeast/northnorthwest asymmetry of rainfall, which leads to the seasonal south-southeast/northwest asymmetry of rainfall.

During Spring, the ITCZ is closer to Réunion Island (than during Winter) which prevents SF from reaching the island. The Mascareigne anticyclone is still intense. StETW are frequent and strong subsidence motions, which dry the troposphere and lower the height of TWIL, prevent the vertical development of clouds. Since NWER, StETW and ST represent $69 \%$ during Spring and are associated with significant rain, during that season, an inversion of the rainfall gradient is observed with altitude. As a result, Spring is the less rainy season, and often windward, rain at the upper levels $(>2000 \mathrm{~m})$ is less than on the coast $(<250 \mathrm{~m})$.

Our results should help increase the reliability of forecasting models at tropical island scale.

Moreover, this study could be done in other tropical islands in the southwest Indian Ocean (e.g. Mauritius, Seychelles) to figure out whether the different types of identified weather patterns affect their rainfall distributions similarly. In particular, the role of the orography could be assessed. This method could also be applied with different types of weather patterns in the islands of other basins (e.g. Atlantic, Pacific), and, additionaly, at a subcontinent scale (e.g. South Africa).

MJO strongly affects rainfall in South Africa (Pohl et al., 2009) and tropical cyclone genesis over the south Indian 
Ocean (Bessafi and Wheeler, 2006). The impact of forcings such as MJO and E1 Niño on the interannual variations of the weather patterns could be analysed for the southwest Indian Ocean and other basins.

Finally, this study will be extended in Réunion Island to analyse the variation of the raindrops (size, velocity) as a function of the weather types.

\section{ACKNOWLEDGEMENTS}

We acknowledge the research program EROVEG (Erosion and Vegetation in Réunion island, 2015-2017) funded by the Ministry of Overseas France (decree $n^{\circ} 1975$, general secretary for regional affairs) for financial support. We also want to thanks Ryan Neely from Leeds University and Clara Alarcon for correcting the manuscript. Finally, thanks a lot to the referee for their work to improve this article.

\section{ORCID}

Anne Réchou (10) https://orcid.org/0000-0002-2312-5434

Francois Bonnardot (10) https://orcid.org/0000-0002-87292020

\section{REFERENCES}

Anderson, T.W. (1984) An Introduction to Multivariate Statistical Analysis, 2nd edition. New York, NY: Wiley.

Andrew, G., Arora, R., Bilmes, J. and Livescu, K. (2013) Deep canonical correlation analysis. In: Proceedings of the 30th International Conference on Machine Learning, Atlanta, GA. PMLR, Vol. 28(3), 1247-1255.

Arora, R. and Livescu, K. (2013). Multi-view CCA-based acoustic features for phonetic recognition across speakers and domains. In: 2013 IEEE International Conference on Acoustics, Speech, and Signal Processing (ICASSP), Vancouver, BC, Canada, 26-31 May 2013, 7135-7139. IEEE.

Badosa, J., Haeffelin, M. and Chepfer, H. (2013) Scales of spatial and temporal variation of solar irradiance on Réunion tropical Island. Solar Energy, 88, 42-56.

Barcelo, A. (1996) Analyse des mécanismes hydrologiques en domaine volcanique insulaire tropical à relief jeune. Apports à la connaissance du bilan hydrique. Thesis, Massif du Piton de la Fournaise, Ile de la Réunion, 266 p.

Barcelo, A. and Coudray, J. (1996) Nouvelle carte des isohyètes annuelles et des maxima pluviométriques sur le massif du Piton de la Fournaise (Ile de la Réunion). Revue des sciences de l'eau, 9, 457-484. https://doi.org/10.7202/ 705262ar.

Bessafi, M. and Wheeler, M.C. (2006) Modulation of south Indian Ocean tropical cyclones by the Madden-Julian oscillation and convectively coupled equatorial waves. Monthly Weather Review, 134, 638-656. https://doi.org/10.1175/ MWR3087.1.

Binaku, K., O'Brien, T., Schmeling, M. and Fosco, T. (2013) Statistical analysis of aerosol species, trace gasses, and meteorology in Chicago. Environmental Monitoring and Assessment, 185(9), 7295-7308.

Brunet, G., Shapiro, M., Hoskins, B., Moncrieff, M., Dole, R.M., Kiladis, G.N., Kirtman, B., Lorenc, A., Mills, B., Morss, R., Polavarapu, S., Rogers, D., Schaake, J. and Shukla, J. (2010) Collaboration of the weather and climate communities to advance subseasonal-to-seasonal prediction. Bulletin of the American Meteorological Society, 91, 1397-1406.

Cao, G., Giambelluca, T.W., Stevens, D.E. and Schroeder, T.A. (2007) Inversion variability in the Hawaiian trade wind regime. Journal of Climate, 20, 1145-1160.

Carrillo, J., Guerra, J.C., Cuevas, E. and Barrancos, J. (2016) Characterization of the marine boundary layer and the trade-wind inversion over the sub-tropical North Atlantic. Boundary-Layer Meteorology, 158, 311-330. https://doi.org/ 10.1007/s10546-015-0081-1.
Cheng, X. and Wallace, J.M. (1993) Cluster analysis of the Northern Hemisphere wintertime 500-hPa height field. Journal of the Atmospheric Sciences, 50, 2674-2696. https://doi.org/10.1175/1520-0469(1993)050,2674:CAOTNH.2. $0 . \mathrm{CO} ; 2$.

Choukri, K. and Chollet, G. (1986) Adaptation of automatic speech recognizers to new speakers using canonical correlation analysis techniques. Speech Communication, 1, 95-107.

Christiansen, B. (2007) Atmospheric circulation regimes: can cluster analysis provide the number? Journal of Climate, 20, 2229-2250.

Grindinger, C.M. (1992) Temporal variability of the trade wind inversion measured with a boundary layer vertical profiler. M.S. Thesis, Department of Meteorology, University of Hawaii at Mānoa, 93 pp.

Halios, C.H., Helmi, C.G., Flocas, H.A., Nyeki, S. and Assimakopoulos, D.N. (2012) On the variability of the surface environment response to synoptic forcing over complex terrain: a multivariate data analysis approach. Meteorology and Atmospheric Physics, 118, 107-115. https://doi.org/10.1007/s00703-0120209-5.

Hevesi, J.A., Istok, J.D. and Flint, A.L. (1992) Precipitation estimation in mountainous terrain using multivariate geostatistics: I. Structural analysis. Journal of Applied Meteorology, 31, 661-676.

Hotelling, H. (1936) Relations between two sets of variates. Biometrika, 28, 321-377.

$\mathrm{Hu}$, Y., Li, D. and Liu, J. (2007) Abrupt seasonal variation of the ITCZ and the Hadley circulation. Geophysical Research Letters, 34(18), L18814,1-5. https://doi.org/10.1029/2007GL030950.

Jolliffe, I.T. (2002) Principal Component Analysis, Series Springer Series in Statistics. 2nd Edition, Springer, XXIX, 487 pp. 28.

Kim, T.-K., Wong, S.-F. and Cipolla, R. (2007) Tensor canonical correlation analysis for action classification. In IEEE Conference on Computer Vision and Pattern Recognition, Minneapolis, MN, 17-22 June 2007, 1-8. IEEE.

Lamarque, P. and Jourdain, S. (1994) Elaboration de longues séries climatologiques homogènes pour l'étude de l'évolution climatique. La Météorologie, 8e série, 7, 61-69.

Le Borgne, J. (1987) Climatologie du Sud Ouest de l'Océan Indien. le cas de l'Ile Maurice ( 2 tomes). Paris: ORSTOM, (204), 358 p. +318 p. (Travaux et Documents de l'ORSTOM; 204). ISBN 2-7099-0827-1.

Lesouëf, D., Gheusi, F., Delmas, R. and Escobar, J. (2011) Numerical simulations of local circulations and pollution transport over Réunion Island. Annals of Geophysics, 29, 53-69.

Lis-Gutiérrez, J.P., Reyna-Niño, H.E., Gaitán-Angulo, M., Viloria, A. and Abril, J.E.S. (2018) Hierarchical ascending classification: an application to contraband apprehensions in Colombia (2015-2016). In: Tan, Y. , Shi, Y. and Tang, Q. (Eds.) DMBD 2018. Lecture Notes in Computer ScienceData Mining and Big Data, Vol. 10943. Cham: Springer.

Littmann, T. (2000) An empirical classification of weather types in the Mediterranean Basin and their interrelation with rainfall. Theoretical and Applied Climatology, 66, 161-171.

Macron, C., Richard, Y., G.T., B.M., Pohl, B., Ratiarison, A. and Razafindrabe, A. (2016) Intraseasonal rainfall variability over Madagascar. Monthly Weather Review, 144(5), 1877-1885. https://doi.org/10.1175/MWR-D-15-0077.1.

Martinez, C., Campins, J., Jansa, A. and Genoves, A. (2008) Heavy rain events in the western Mediterranean: an atmospheric pattern classification. Advances in Science and Research, 2, 61-64.

Mendoca, B.G. and Iwaoka, W.T. (1969) The trade wind inversion the slopes of Mauna Loa, Hawaii. Journal of Applied Meteorology, 8(2), 213-219. https://doi.org/10.1175/1520-0450(1969)008<0213:TTWIAT>2.0.CO;2.

Meuzelaar, H.L.C., Yun, Y.S., Chakravarty, T. and Metcalf, G.S. (1992) Computer-enhanced pyrolysis mass spectrometry: a new window on coal structure and reactivity. In: Meuzelaar, H.L.C. (Ed.) Advances in Coal Spectroscopy. New York, NY: Plenum Press, pp. 275-294. https://doi.org/10.1007/ 978-1-4899-3671-4_12.

Michelangeli, R.A., Vautard, R. and Legras, B. (1995) Weather regimes: recurrence and quasi-stationarity. Journal of the Atmospheric Sciences, 52, 1237-1256.

Montanarella, L., Bassani, M.R. and Bréas, O. (1995) Chemometric classification of some European wines using pyrolysis mass spectrometry. Rapid Communications in Mass Spectrometry, 9(15), 1589-1593. https://doi.org/10.1002/rcm. 1290091525.

Morel, B., Pohl, B., Richard, Y., Bois, B. and Bessafi, M. (2014) Regionalizing rainfall at very high resolution over La Réunion Island using a regional 
climate model. Monthly Weather Review, 142, 2665-2686. https://doi.org/10. 1175/MWR-D-14-00009.1.

Ntegeka, V. and Willems, P. (2008) Trends and multidecadal oscillations in rainfall extremes, based on a more than 100-year time series of $10 \mathrm{~min}$ rainfall intensities at Uccle, Belgium. Water Resources Research, 44, w07402. https $J /$ doi.org/10.1029/2007WR006471.

Plaut, G. and Simonnet, E. (2001) Large-scale circulation classification, weather regimes, and local climate over France, the Alps and western Europe. Climate Research, 17, 303-324.

Pohl, B., Janicot, S., Fontaine, B. and Marteau, R. (2009) Implication of the Madden-Julian Oscillation in the 40-day variability of the West African monsoon. Journal of Climate, 22, 3769-3785. https://doi.org/10.1175/ 2009JCLI2805.1.

Quetelard, H., Bessemoulin, P., Cerveny, R.S., Peterson, T.C., Burton, A. and Boodhoo, Y. (2009) Extreme weather: world-record rainfalls during tropical cyclone Camede. Bulletin of the American Meteorological Society, 90, 603-608.

Réchou, A. and Kirkwood, S. (2015) Investigation of weather anomalies in the low-latitude islands of the Indian Ocean in 1991. Annals of Geophysics, 33, 789-804. https://doi.org/10.5194/angeo-33-789-2015.

Réchou, A., Narayana Rao, T., Bousquet, O., Plu, M. and Decoupes, R. (2014) Properties of rainfall in a tropical volcanic island deduced from UHF wind profiler measurements. Atmospheric Measurement Techniques, 7, 409-418. https://doi.org/10.5194/amt-7-409-2014.

Robert, R. (1986). Climat et hydrologie à la Réunion: étude typologique et régionale des pluies et de l'écoulement. Thesis, Univ. de Montpellier, 438 pp.

Rodríguez-Puebla, C., Encinas, A.H., Nieto, S. and Garmendia, J. (1998) Spatial and temporal patterns of annual precipitation variability over the Iberian Peninsula. International Journal of Climatology, 18, 299-316. https://doi.org/ 10.1002/(SICI)1097-0088(19980315)18:3<299:: AID-JOC247>3.0.CO;2-L.

Rousseeuw, P.J. (1987) Silhouettes: a graphical aid to the interpretation and validation of cluster analysis. Journal of Computational and Applied Mathematics, 20, 53-65.

Sargin, M.E., Yemez, Y. and Tekalp, A.M. (2007) Audiovisual synchronization and fusion using canonical correlation analysis. IEEE Transactions on Multimedia, 9(7), 1396-1403.

Shapiro, M., Shukla, J., Brunet, G., Nobre, C., Béland, M., Dole, R., Trenberth, K., Anthes, R., Asrar, G., Barrie, L. and Bougeault, P. (2010) An Earth-system prediction initiative for the twenty-first century. Bulletin of the American Meteorological Society, 91, 1377-1388.

Tran, L.T. (1995) Relationship between the inversion and rainfall on the Island of Maui. M.S. Thesis, Department of Geography, University of Hawaii at Mānoa, 115 pp.

Vert, J.-P. and Kanehisa, M. (2004)Graph-driven features ex traction from microarray data using diffusion kernels and kernel CCA. In: Thrun, S. , Saul, L.K. and Schölkopf, B. (Eds.) Advances in Neural Information Processing Systems, Vol. 16. Cambridge, MA: MIT Press, pp. 1449-1455.

Vigaud, N., Pohl, B. and Crétat, J. (2012) Tropical-temperate interactions over southern Africa simulated by a regional climate model. Climate Dynamics, 39(12), 2895-2916. https://doi.org/10.1007/s00382-012-1314-3.

Vinokourov, A., Shawe-Taylor, J. and Cristianini, N. (2004) Inferring a semantic representation of text via cross-language correlation analysis. In: Thrun, S., Saul, L.K. and Schölkopf, B. (Eds.) Advances in Neural Information Processing Systems, 16. Cambridge, MA: MIT Press, pp. 1497-1504.
Ward, J. (1963) Hierarchical grouping to optimize an objective function. Journal of the American Statistical Association, 58, 236-244. https://doi.org/10.1080/ 01621459.1963.10500845.

Willems, P. (2013) Multidecadal oscillatory behaviour of rainfall extremes in Europe. Climate Change, 120, 931-944.

How to cite this article: Réchou $A$, Flores $\mathrm{O}$, Jumaux G, et al. Spatio-temporal variability of rainfall in a high tropical island: Patterns and large-scale drivers in Réunion Island. $Q J R$ Meteorol Soc 2019;145:893-909. https://doi.org/10.1002/qj.3485

\section{A PPENDIX: CLASSIFICATION OF THE LARGE-SCA LE CANONICAL VA RIA BLES}

Classification on the large-scale canonical variables and determination of the number of classes (weather patterns) are presented in Figure A1.

Different steps of the classification are presented on the left side, while the results of dendrogram, and the different tests, are presented on the right side. Inspection of the dendrogram shows from two to eight nuclei. First of all, two classes of dates are created as a function of the two closer groups of $\mathrm{COV}$ by the k-means method. Then it is repeated until eight classes are completed. The optimal number of classes is given by the results of different statistical tests. The different tests obtained for the DJFM (Summer) season is also presented in order to define the optimal number of clusters (or classes). A faster silhouette test (based on the comparison of its tightness and separation of the clusters) should be the highest (yellow line, which correspond to the maximum of classes). The no-concordance parameter (Lamarque and Jourdain, 1994, blue line), here in \%, should be as low as possible (classes must be concordant, which gives six classes), while classifiability index should be high (five classes), which is the case for six classes and five classes respectively. Based on these criteria, five and six large composite classes were drawn. Then, it is observed visually with the different composite classes with $R R$ and $Z_{875}$ that six classes are pertinent to analyse the rain for Summer. 

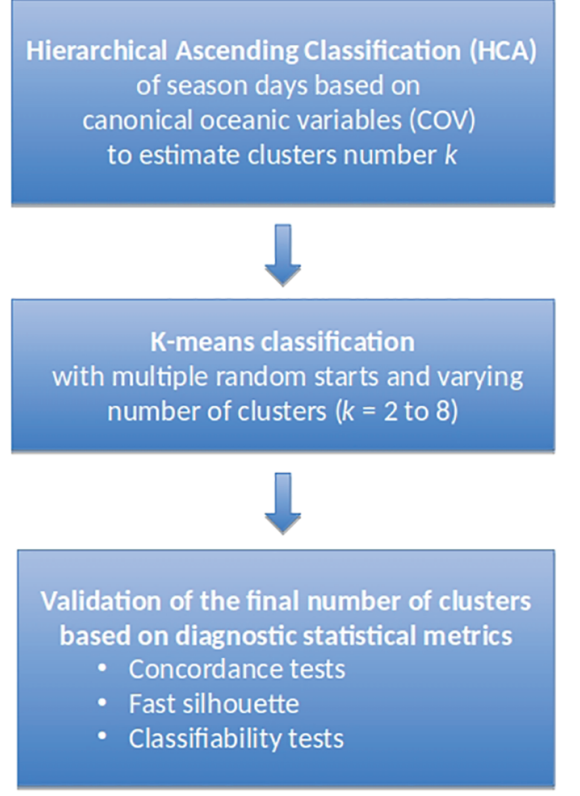

Dendrogram of days classified in clusters by HAC

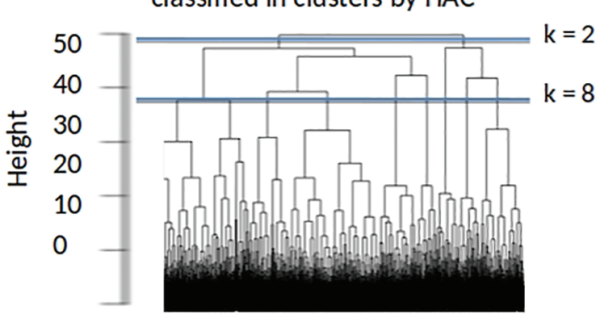

Influence of clusters number on diagnostic metrics for one example season

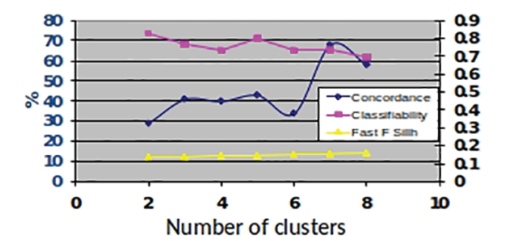

FIGURE A1 Method description for the definition of synoptic weather regimes. In each defined season, the HAC is performed on the four retained canonical variables at oceanic scale for all days over the 37-year study period. A range of a priori number of clusters is retained a priori for the following k-means analyses. The results of multiple k-means analyses are compared using different statistical metrics for classification diagnosis, which allow us to estimate the optimal number of regimes with the tested range [Colour figure can be viewed at wileyonlinelibrary.com]. 